Caracterização acústica da vogal átona final /e/ no português porto-alegrense e no espanhol uruguaio | 41

\title{
CARACTERIZAC̣ÃO ACÚSTICA DA VOGAL ÁTONA FINAL /e/ NO PORTUGUÊS PORTO-ALEGRENSE E NO ESPANHOL URUGUAIO
}

\author{
Bruna da Rosa de Los Santos ${ }^{8}$ \\ Ubiratã Kickhöfel Alves ${ }^{9}$
}

RESUMO: É apresentada, neste artigo, uma comparação acústica referente à altura, anterioridade/posterioridade e duração vocálica da vogal átona final /e/, entre a variedade do Português Brasileiro (PB) falada em Porto Alegre/RS e a variedade do Espanhol falada em Montevidéu/Uruguai. Para isso, contamos com a participação de monolíngues das respectivas línguas. Tais caracterizações acústicas se fazem necessárias, dado que uma grande parte dos pesquisadores brasileiros têm investido no estudo do processo de desenvolvimento de Espanhol como Segunda Língua (L2) por parte de aprendizes também brasileiros. Além disso, tanto a literatura do PB como a da Língua Espanhola carecem de descrições acústicas das vogais átonas. Os dados apresentados neste artigo foram obtidos a partir de duas Tarefas de Leitura, uma em Português e outra em Espanhol. Os resultados indicam que a vogal átona final /e/ do PB é mais curta, mais alta e mais centralizada do que a sua contraparte no Espanhol uruguaio.

Palavras-chave: vogal átona final /e/; Português Brasileiro; Espanhol Uruguaio; descrição acústica.

ABSTRACT: In this article, we provide an acoustic comparison between the word-final unstressed vowel /e/ produced in Brazilian Portuguese (Porto Alegre-RS variety) and in Spanish (Montevideo-Uruguay variety). In order to do so, we collected data from monolingual participants of each language. We consider this acoustic description to be necessary, as many researchers have investigated the learning of L2 Spanish in the Brazilian scenario and acoustic descriptions in these two languages are

${ }^{8}$ Mestre em Letras em Estudos da Linguagem - Psicolinguística pela Universidade Federal do Rio Grande do Sul-UFRGS.

${ }^{9}$ Doutor em Linguística Aplicada pela Pontifícia Universidade Católica do Rio Grande do Sul, PUC/RS. Professor Adjunto da Universidade Federal do Rio Grande do Sul, UFRGS. 
42 | Bruna da Rosa de Los Santos e Ubiratã Kickhöfel Alves

still few, especially regarding unstressed vowels. The data were obtained in reading tasks in the two languages, and the results suggest that the wordfinal unstressed /e/ in Brazilian Portuguese is shorter, higher and more centralized than in Uruguayan Spanish.

Key-words: word-final unstressed final /e/; Brazilian Portuguese; Uruguayan Spanish; acoustic description.

\section{INTRODUÇÃO}

Neste artigo, apresentamos uma comparação acústica entre a vogal átona final /e/ do Português Brasileiro (PB), falado em Porto Alegre/RS, e a mesma vogal do Espanhol na variedade de Montevidéu (Uruguai). Devido à vasta literatura sobre vogais no Brasil, principalmente a de cunho variacionista (AMARAL, 2000; BISOL, 1981, 2003; BORTONI et al., 1991; CALLOU, LEITE, 2000; CÂMARA JR., 1970; CARNIATO, 2000; MACHRY DA SILVA, 2009; MARGOTTI, 2004; MILESKI, 2013; SCHMITT, 1987; VIEIRA, 1994, 2002; dentre outros), conhecemos a pluralidade linguística que perpassa o território brasileiro. No Sul, por exemplo, dado o contato com os mais diversos dialetos de imigrantes e com o Espanhol nas zonas de fronteira, o PB foi se modificando, abrindo espaço para falares diversos. Sendo assim, tanto do ponto de vista fonético-fonológico quanto do lexical, a variedade sulista do PB é diversa e também distinta do restante do país. No entanto, é importante apontar que a fala da capital gaúcha se distingue das variedades utilizadas pelos falantes de fronteira e daqueles pertencentes às comunidades bilíngues. Dado o fato de que o falar porto-alegrense é influenciado pelos mais diversos contatos linguísticos, o mesmo apresenta particularidades próprias, justificando o interesse investigativo de pesquisas como a que propomos neste trabalho.

De forma semelhante, a Língua Espanhola é também plural, visto que é falada em 21 países, abrangendo, portanto, elementos culturais e linguísticos específicos de cada país. Assim, há uma grande variação dialetal na Língua Espanhola. Dessa forma, não é difícil encontrarmos brasileiros que compreendem muito bem o Espanhol Uruguaio e o Argentino, mas têm dificuldade com o Espanhol de outros dialetos, como o Espanhol Chileno, o Espanhol Peruano ou o Espanhol Ibérico. Contudo, apesar de tanta diversidade, o sistema vocálico do Espanhol é considerado mais estável do que o sistema vocálico do Português. Isso se deve ao fato de que tal sistema não apresenta grandes mudanças fonético- 
Caracterização acústica da vogal átona final /e/ no português porto-alegrense e no espanhol uruguaio | 43 fonológicas, mantendo, na maioria de seus dialetos, cinco vogais, ao contrário do $\mathrm{PB}$, que varia de sete a três vogais, a depender da posição silábica e da região brasileira.

No entanto, considerando as peculiaridades de cada variedade linguística, torna-se difícil generalizar certos resultados de produção vocálica e até mesmo de desenvolvimento vocálico por parte de bilíngues de diferentes regiões brasileiras. No caso de desenvolvimento bilíngue, é preciso, de partida, conhecer as características da variedade da língua materna (L1) do aprendiz, assim como as características típicas da Segunda Língua (L2). Como muitos pesquisadores brasileiros têm se dedicado ao estudo do desenvolvimento de Espanhol como Segunda Língua (L2), tem sido necessário mapear o sistema vocálico, tanto do PB como do Espanhol, levando em consideração as diferenças regionais. Dessa forma, uma descrição acústica detalhada pode prover insumos para o levantamento de novas hipóteses de pesquisa no campo de desenvolvimento de L2. Tal comparação se faz necessária, considerando-se a escassez de trabalhos com detalhamento acústico dessas variedades, principalmente no que se refere às vogais átonas.

Sendo assim, nesta pesquisa temos como objetivo mapear as produções monolíngues do PB porto-alegrense e do Espanhol de Montevidéu, com relação à vogal átona final /e/, apresentando também uma comparação entre essas duas línguas no que diz respeito aos parâmetros de altura, anterioridade/posterioridade e duração (absoluta e relativa) vocálicas. Apoiados na literatura descritiva, variacionista e também acústica de ambas as línguas, levantamos a seguinte hipótese de pesquisa: haverá diferença significativa entre a vogal átona final /e/ do PB porto-alegrense e a sua contraparte do Espanhol, dado que a vogal gaúcha será mais alta (maior F1 - em Bark), mais centralizada (maior F2 - em Bark) e mais curta (menor duração absoluta e relativa).

Esperamos, com o presente trabalho, prover dados empíricos que contribuirão para a descrição dos dialetos de Português de Porto Alegre e do Espanhol de Montevidéu, de modo a prover, também, insumos para futuros estudos sobre a aquisição do Espanhol (L2) por brasileiros. A seguir, apresentamos uma breve revisão da literatura referente ao sistema vocálico átono do Português Brasileiro, focando na variedade de Porto Alegre, e do Espanhol de Montevidéu. 
44 | Bruna da Rosa de Los Santos e Ubiratã Kickhöfel Alves

\section{SOBRE AS VOGAIS ÁTONAS NO PB E NO ESPANHOL}

Nesta seção descrevemos, separadamente, estudos sobre os sistemas vocálicos átonos do PB e do Espanhol. Ressaltamos que o nosso foco recairá sobre as variedades do $\mathrm{PB}$ porto-alegrense e do Espanhol falado em Montevidéu.

\subsection{O sistema vocálico átono final do Português Brasileiro}

Muito conhecido é o trabalho descritivo de Câmara Jr. (1970) sobre o sistema vocálico da variedade carioca do Português Brasileiro (PB), pois é a partir desse que se começam a pensar os processos fonéticofonológicos ${ }^{10}$ que dizem respeito às vogais, ocorridos na produção da fala. Segundo Câmara Jr. (1970), o sistema vocálico do PB conta com sete vogais em posição tônica (i, e, $\varepsilon, a, o, o, u$ ), enquanto que na posição átona têm-se cinco vogais ( $\mathrm{u}, \mathrm{o}, \mathrm{a}, \mathrm{e}, \mathrm{i}$ - posição pretônica), quatro vogais (u, a, e, i - posição postônica não-final) ou três vogais (u, a, i - posição postônica final). Conforme aponta Bisol (2010), "A passagem de um subsistema para outro é identificada pela elevação gradual da vogal média $(\varepsilon, \rho>\mathrm{e}, \mathrm{o}>\mathrm{i}, \mathrm{u})$, que ocorre de acordo com o grau de enfraquecimento da sílaba: as pretônicas são relativamente menos fortes do que as tônicas e as átonas postônicas são as mais fracas." (op. cit., p. 42).

De acordo com tal caracterização, na posição átona, que é a posição de interesse da pesquisa a ser desenvolvida, o sistema passa de sete vogais para cinco, quatro ou três vogais, como veremos a seguir.

\subsubsection{A variação das vogais átonas finais do PB sulista}

Alguns pesquisadores (CARNIATO, 2000; LINK, 2015; MACHRY DA SILVA, 2009; MARGOTTI, 2004; MILESKI, 2013; SCHMITT, 1987; VIEIRA, 1994, 2002), principalmente à luz da Teoria Variacionista, contestaram os postulados de Câmara Jr. (1970), ao encontrarem variedades nas quais o sistema vocálico não é estanque, mas

${ }^{10}$ Consideramos que tais processos não seriam puramente fonológicos, mas, sim, deveriam ser chamados de 'fonético-fonológicos', uma vez que não concebemos a divisão dicotômica entre as áreas de 'fonética' $\mathrm{e}$ 'fonologia' dentro da perspectiva dinâmica de língua (BECKNER et al., 2009; DE BOT et al., 2013) que assumimos. 
Caracterização acústica da vogal átona final /e/ no português porto-alegrense e no espanhol uruguaio | 45 variável dentro de uma mesma comunidade de fala, e seu uso controlado por fatores linguísticos e "não-linguísticos"11. Grande parte destes estudos foram desenvolvidos no sul do Brasil, considerando o falar típico de comunidades de imigrantes e de seus descendentes. No entanto, para Bisol (2003), embora ainda haja variação em algumas comunidades de fala, o processo de produção das vogais átonas finais como altas vem se impondo, tendendo a generalizar-se. Portanto, haveria um processo de mudança linguística em curso.

Especificamente em Porto Alegre, variedade dos participantes deste estudo, o processo de elevação/alçamento, em posição átona final, ainda que variável, é uma característica marcante desta fala, tendo em vista que o não-alçamento se aplica em poucos casos (BISOL, 2003; SOUZA, 2015; VIEIRA, 1994, 2002), sendo condicionares desse processo variável, principalmente, os contextos fonético-fonológicos nos quais estão inseridas as vogais átonas finais. Além disso, quando comparada com regiões de bilíngues ou de fronteira, Porto Alegre possui o mais alto índice de elevação/alçamento, o que permite que alguns pesquisadores o tratem, inclusive, como um fenômeno categórico e não mais variável.

Mais recentemente, dada a necessidade de olhar para o sistema vocálico de uma forma menos categórica, cresceu o interesse pela obtenção de dados acústicos. A seguir, apresentamos um apanhado geral dos trabalhos com detalhamento acústico das vogais átonas finais do PB.

\subsubsection{Caracterização acústica das vogais átonas finais do PB}

Em termos acústicos, a literatura conta com os seguintes estudos de vogais átonas postônicas finais: Callou, Moraes e Leite (1996, 2002), Silva (2012), Matzenauer et al. (2015) e Brisolara e Solé (2016). No entanto, destes trabalhos, apenas o primeiro apresenta dados acústicos da variedade porto-alegrense. Ainda que o nosso foco recaia sobre a

11 Dentro de uma perspectiva dinâmica de língua é, no mínimo, incoerente utilizar os termos não-linguístico e extralinguístico, pois há grande interação de fatores/variáveis na língua, que não só interagem com o sistema linguístico, como também o constituem. Dessa forma, nada está "fora" do sistema linguístico. No entanto, estes termos (não-linguístico e extralinguístico) são utilizados na maioria dos estudos mencionados nesta seção, pois são trabalhos de cunho formal e tradicional. Por isso, tais termos poderão aparecer nesta revisão bibliográfica. 


\section{6 | Bruna da Rosa de Los Santos e Ubiratã Kickhöfel Alves}

variedade sulista, é importante mencionar que incluímos o trabalho de Silva (2012), embora o mesmo trate do PB brasiliense, porque em tal estudo há uma descrição duracional da vogal átona final. Além disso, segundo Silva (2012), o padrão acústico das vogais brasilienses se assemelha mais ao das vogais da capital gaúcha do que ao de outras variedades, o que permite a comparação entre as mesmas.

Os dados coletados por Callou, Moras e Leite $(1996,2002)$ são referentes a 15 entrevistas, com falantes masculinos, coletadas através do Projeto Norma Urbana Culta (NURC). Silva (2012), por sua vez, faz uso de uma Tarefa de Leitura, na qual as palavras-alvo apresentam-se inseridas na frase-veículo "Digo X baixinho" (sendo X correspondente aos estímulos selecionados pela autora).

Já o estudo de Matzenauer et al. (2015) conta com uma amostra de 4 participantes adultos ( 2 homens e 2 mulheres), moradores da cidade de Pelotas/RS. Os dados de produção foram obtidos através da leitura de frases-veículo (instrumento adaptado de Rauber, 2008), nas quais foram inseridos logatomas com as vogais-alvo. Utilizaram-se como contextos linguísticos, para a construção dos logatomas, as consoantes surdas $/ \mathrm{p}, \mathrm{t}$, $\mathrm{k}, \mathrm{f}, \mathrm{s} /$. Além disso, é importante mencionar que os dados foram normalizados a partir do método Lobanov.

Por último, em Brisolara e Solé (2016), embora haja uma amostra de participantes reduzida (2 informantes apenas), é realizado um mapeamento das vogais médias /e/ e /o/ em posição postônica final. Contudo, o objetivo não é analisar estas produções vocálicas em $\mathrm{PB}$ como Primeira Língua (L1), mas a produção dessas vogais por colombianas, aprendizes de Português como Segunda Língua/Língua Estrangeira (PLE). Para isso, as pesquisadoras contam com um grupo controle de duas falantes nativas do Português Brasileiro, nascidas e criadas em Rio Grande/RS, para a comparação com o grupo bilíngue. Para a obtenção dos dados de fala, foi utilizada uma Tarefa de Leitura de palavras, contendo as vogais /e/ e /o/ átonas em posição final. É importante mencionar que as consoantes antecedentes à vogal alvo eram oclusivas (Ex.: $\mathrm{p}=$ sapo/golpe; $\mathrm{b}=$ cabo/plebe; $\mathrm{k}=$ frasco/saque; $\mathrm{g}=$ tango/dengue) e fricativas $(\mathrm{f}=$ golfo/gafe; $\mathrm{s}=$ recurso/suspense $)$.

Na Tabela 1, a seguir, é possível visualizar os dados reportados nos estudos mencionados referentes à produção da vogal átona final /e/, a qual é mapeada também na presente pesquisa. 
Caracterização acústica da vogal átona final /e/ no português porto-alegrense e no espanhol uruguaio $\mid 47$

Tabela 1: Dados acústicos da vogal postônica final /e/ no Português Brasileiro

\begin{tabular}{c|c|c|c|c}
\hline Autor (es) & Cidade/Estado & $\begin{array}{c}\mathrm{F} 1 \\
(\mathrm{~Hz})\end{array}$ & $\begin{array}{c}\mathrm{F} 2 \\
(\mathrm{~Hz})\end{array}$ & $\begin{array}{c}\text { Duração } \\
(\mathrm{ms})\end{array}$ \\
\hline $\begin{array}{c}\text { Callou, Moras e Leite } \\
(1996,2002)\end{array}$ & $\begin{array}{c}\text { Porto Alegre } \\
\text { RS }\end{array}$ & 387 & 1880 & - \\
\hline $\begin{array}{c}\text { Silva } \\
(2012)\end{array}$ & $\begin{array}{c}\text { Brasília } \\
\text { DF }\end{array}$ & 416 & 2092 & 88 \\
\hline $\begin{array}{c}\text { Matzenauer et al. } \\
(2015)\end{array}$ & $\begin{array}{c}\text { Pelotas } \\
\text { RS }\end{array}$ & 320 & 2018 & - \\
\hline $\begin{array}{c}\text { Brisolara e Solé } \\
(2016)\end{array}$ & $\begin{array}{c}\text { Rio Grande } \\
\text { RS }\end{array}$ & 414 & 1681 & - \\
\hline
\end{tabular}

Fonte: os autores.

Como é possível observar na Tabela 1 , a cidade de Pelotas apresenta a vogal átona final /e/ mais baixa $(\mathrm{M}=320 \mathrm{~Hz})$, enquanto que Brasília apresenta a produção mais alta $(\mathrm{M}=416 \mathrm{~Hz})$. A produção de Porto Alegre $(\mathrm{M}=387 \mathrm{~Hz})$, por sua vez, fica mais próxima à de Brasília, assim como a produção de Rio Grande $(\mathrm{M}=414 \mathrm{~Hz})$. Quanto ao eixo de anterioridade/posterioridade, na ordem de produção mais anterior à mais centralizada, temos Brasília com a vogal /e/ mais anterior $(\mathrm{M}=2092 \mathrm{~Hz})$, Pelotas $(\mathrm{M}=2018 \mathrm{~Hz})$, Porto Alegre $(\mathrm{M}=1880 \mathrm{~Hz})$ e, por último, Rio Grande $(\mathrm{M}=1681 \mathrm{~Hz})$, sendo esta última, portanto, a vogal mais centralizada. Em termos duracionais, contamos apenas com os dados de Silva (2012), estes referentes a Brasília $(M=59 \mathrm{~ms})$.

$\mathrm{Na}$ subseção a seguir, apresentamos um apanhado geral da literatura sobre as vogais da Língua Espanhola.

\subsection{O sistema vocálico átono do Espanhol}

Tradicionalmente, considerando-se a distinção entre fonética e fonologia, segundo Conde (2001), o sistema vocálico do Espanhol, independente da variedade, fonologicamente é constituído por cinco vogais (i, e, a, o, u), classificadas como vogal inicial fechada (vogal i), vogal final fechada (vogal u), vogal média inicial-central (vogal e), vogal média final-central (vogal o) e vogal central aberta (vogal a). No entanto, assim como o sistema vocálico brasileiro, o Espanhol também é caracterizado 
48 | Bruna da Rosa de Los Santos e Ubiratã Kickhöfel Alves

por variação. A seguir, detalhamos, ainda que brevemente, algumas das principais características variáveis das vogais da Língua Espanhola.

\subsubsection{A variação das vogais átonas finais do Espanhol}

Ainda dentro da distinção estruturalista, Navarro Tomás (2004) defende a influência da estrutura silábica, da natureza dos sons que acompanham as vogais e a influência do acento de intensidade, o que caracteriza um olhar mais fonético para o sistema vocálico. Existe, portanto, uma relação entre as influências levantadas por Navarro Tomás (2004) e as influências encontradas nas pesquisas sociolinguísticas sobre as vogais brasileiras, visto que, em ambas as literaturas, se concebe um papel às consoantes vizinhas (precedente ou seguinte) na produção vocálica. Sobre as vogais átonas, definidas como não-acentuadas por Navarro Tomás (2004), essas são consideradas por sua tendência à relajación (relaxamento, descontração), pois

O timbre das vogais não-acentuadas depende, especialmente, do esmero ou descuido com que se fala e do grau relativo da intensidade correspondente a sua posição. Em pronunciação lenta ou enfática se mantêm claras e distintas. Em linguagem rápida e familiar relaxam sua articulação e tomam um timbre menos definido e preciso (NAVARRO TOMÁS, 2004, p. 44).

Portanto, tais vogais sofrem mudanças articulatórias e, consequentemente, acústicas, quando em fala coloquial. Alguns contextos são mais favorecedores do fenômeno de relajación, como vogais átonas de paroxítonas diante de pausa e de proparoxítonas (dessas, a vogal final é menos 'relaxada/descontraída' do que a da penúltima sílaba) ${ }^{12}$. Além disso, conforme Navarro Tomás (2004), ainda que em menor frequência, a vogal antecedente à vogal acentuada também pode ser 'relajada'.

12 Em Espanhol, as sílabas acentuadas recebem as seguintes definições: agudas (quando a última sílaba é a tônica), llanas/graves (quando a penúltima sílaba é tônica), esdrújulas (quando a antepenúltima sílaba é tônica) e sobresdrújulas (quando a ante-antepenúltima sílaba é tônica). Exemplos de vogais 'relajadas' nestes dois contextos são: 'catorcée; 'húmedo' 
Caracterização acústica da vogal átona final /e/ no português porto-alegrense e no espanhol uruguaio | 49

Quanto ao fenômeno de produção das vogais átonas finais como altas, comum em variedades do Português Brasileiro, o mesmo não é considerado característica do Espanhol. Alguns estudos sinalizam a presença deste fenômeno (LIPSKI, 2007; REAL ACADEMIA ESPAÑOLA, 2011), mas em poucas variedades e por influências de línguas indígenas. Dado o contexto de tal fenômeno, o mesmo é muito estigmatizado e não consta nos materiais didáticos de Espanhol como Segunda Língua (L2). No entanto, Luís e García Jurado (1983) classificam trocas vocálicas como em apaliado-apaleado (ea-ia), MediterranioMediterráneo (eo-io), almuada-almohada (oa-ua), ruedor-roedor (oe-ue), peculear-peculiar (ia-ea), moeblería-mueblería (ue-oe) e mensoal-mensual (ua-oa) a partir da noção de neutralização, assim como os fonólogos brasileiros fizeram com a produção das vogais médias em posições átonas. Classificando foneticamente tais modificações como desplazamientos, Luís e García Jurado (1983) afirmam que

É preciso levar em conta que esses desplazamientos se dão em certos registros de fala e não em outros: se observam na fala rápida, na fala regional e na fala familiar, não na pronúncia lenta e esmerada. Ainda que esteja generalizado, ocorre a coexistência de ambas as formas. Dessa forma, um mesmo falante pode dizer pior e peor, puesía e poesía (LUÍS; GARCÍA JURADO, 1983, p. 103).

Além desta colocação, Luís e García Jurado (1983) defendem que a vogal alçada (desplazada) seria um terceiro elemento neutro, ou seja, uma vogal intermediária que, por sua vez, não corresponderia exclusivamente a [i] ou [e], [u] ou [o]. Contudo, em posição postônica final absoluta, a literatura não registra casos de vogal intermediária; inclusive, são pouco frequentes palavras terminadas em [i, u] em Espanhol (ALARCOS LLORACH, 1975; BRISOLARA, SEMINO, 2014).

De forma geral, a literatura em Espanhol considera a produção da vogal média em posição átona final como sendo característica da língua, diferentemente do PB que, por sua vez, apresenta variação entre as vogais médias e altas, sendo a produção alta mais frequente em regiões como Porto Alegre/RS.

A seguir, apresentamos alguns dos estudos acústicos sobre o sistema vocálico Espanhol. 


\subsubsection{Caracterização acústica do sistema vocálico Espanhol}

Em termos acústicos, assim como a literatura carece de descrições acústicas das diversas variedades do Português Brasileiro, ocorre o mesmo com o Espanhol, que, por sua vez, possui uma enorme variação dialetal. Encontramos disponível apenas um estudo sobre a variedade de Montevidéu, sendo o de Santos e Rauber (2016). No entanto, o mesmo trata das vogais em posição tônica. Sobre as vogais átonas, temos o estudo de Butragueño (2011) na Cidade do México, embora o pesquisador reporte uma média entre as vogais tônicas e átonas por ele mapeadas.

Butragueño (2011) investiga as propriedades acústicas (somente altura e anterioridade/posterioridade) do sistema vocálico Espanhol (variedade da Cidade do México), em contexto espontâneo. Buscando caracterizar os sistemas átono e tônico, Butragueño (2011) obtém uma amostra de oito informantes (divididos igualmente por sexo, faixa etária e escolaridade), os quais participam de uma entrevista semi-espontânea para a coleta de dados ${ }^{13}$. Vale ressaltar que Butragueño (2011) apresenta um único valor (média) para as vogais tônicas e átonas, o que dificulta fazer alguma consideração sobre a tonicidade.

Por outro lado, Santos \& Rauber (2016) apresentam dados acústicos para as vogais tônicas do Espanhol, na variedade de Montevidéu/Uruguai - variedade essa com a qual operaremos neste trabalho - com a finalidade de contribuir com estudos na área da fonética e fonologia do Espanhol. O estudo conta com uma amostra de 16 universitários (divididos igualmente entre homens e mulheres), os quais afirmaram ter pouco conhecimento de outras línguas.

A seguir, na Tabela 2, apresentamos os dados acústicos das pesquisas supracitadas.

13 Tais entrevistas pertencem ao Corpus Sociolingüístico de la Ciudad de México (BUTRAGUEÑO; LASTRA, 2011). Disponível em $<$ http://lef.colmex.mx/index.php/investigaciones/corpussociolingueistico-de-laciudad-de-mexico-cscm >. Acesso em: 10 de agosto de 2017. 
Caracterização acústica da vogal átona final /e/ no português porto-alegrense e no espanhol uruguaio $\mid 51$

Tabela 2: Dados acústicos da vogal /e/ no Espanhol

\begin{tabular}{c|c|c|c|c}
\hline Autor (es) & Cidade/País & $\begin{array}{c}\text { F1 } \\
(\mathrm{Hz})\end{array}$ & $\begin{array}{c}\text { F2 } \\
(\mathrm{Hz})\end{array}$ & $\begin{array}{c}\text { Duração } \\
(\mathrm{ms})\end{array}$ \\
\hline $\begin{array}{c}\text { Butragueño } \\
(2011)\end{array}$ & $\begin{array}{c}\text { Cidade do } \\
\text { México, México }\end{array}$ & 574 (homem) & 1772 & - \\
\hline $\begin{array}{c}\text { Santos e Rauber } \\
(2016)\end{array}$ & $\begin{array}{c}\text { Montevidéu, } \\
\text { Uruguai }\end{array}$ & 472 & 2270 & 106 \\
\hline
\end{tabular}

Fonte: os autores.

Como podemos notar na Tabela 2, as produções da vogal átona final /e/ do Espanhol Mexicano, tanto masculina como feminina, são mais baixas $(\mathrm{M}=474 / 516 \mathrm{~Hz})$ do que as produções das vogais tônicas do Espanhol de Montevidéu $(\mathrm{M}=472 \mathrm{~Hz})$. No entanto, a média masculina mexicana é bem próxima à média das tônicas de Montevidéu. Quanto ao eixo de anterioridade/posterioridade, as produções átonas mexicanas são mais centralizadas $(\mathrm{M}=1772 / 2058 \mathrm{~Hz})$ do que as das tônicas de Montevidéu $(\mathrm{M}=2270 \mathrm{~Hz})$. Em termos duracionais, apenas o trabalho de Santos e Rauber (2016) mapeia a duração absoluta da vogal /e/ ( $M=106$ ms), embora em posição tônica.

Considerando os estudos acústicos da Língua Espanhola, embora exista uma discussão sobre a quantidade silábica, pouco sabemos sobre a duração vocálica, propriamente dita. Conforme Navarro Tomás (2004), "a sílaba acentuada é mais longa do que a sílaba não-acentuada. (...) A causa que produz maiores diferenças de duração entre as sílabas é o acento enfático" (op. cit., p. 206). Especificamente sobre a duração vocálica, encontramos a descrição feita na Nueva Gramática de la Lengua Española Fonética y Fonología (REAL ACADEMIA ESPAÑOLA - RAE, 2013), segundo a qual,

Em espanhol, as variações relacionadas à duração vocálica são de natureza fonética e estão vinculadas à tonicidade da vogal, ao seu timbre, à composição da sílaba na qual está inserida, ao contexto consonântico que a rodeia, à estrutura silábica da palavra da qual forma parte e a sua posição no que diz respeito a essa estrutura (op. cit., p. 112). 


\section{2 | Bruna da Rosa de Los Santos e Ubiratã Kickhöfel Alves}

Dessa forma, tanto vogais tônicas como átonas podem variar quanto à duração, devido ao contexto no qual estão inseridas. Conforme a Gramática supracitada, as vogais tônicas têm sua variação condicionada, especificamente, pelo timbre vocálico (portanto, a ordem de maior a menor duração é a seguinte: /a, o, e, u, i/), pela estrutura da palavra (as mais longas são as vogais acentuadas de vozes agudas e as mais curtas são as vogais de vozes esdrújulas) e pela natureza da consoante seguinte. Por outro lado, a variação no padrão duracional das vogais átonas é condicionada pelo número de sílabas da palavra, pela posição da vogal na palavra, pela natureza da consoante seguinte e pela estrutura silábica da sílaba na qual se encontra a vogal átona. Além disso, segundo a Gramática da RAE (2011), "a duração da vogal átona inicial diminui conforme ela se distancia da vogal tônica; além disso, a pretônica tende a ser mais breve do que a postônica. A vogal final é a mais longa das átonas" (op. cit., p.112). Entretanto, embora evidenciada a variação no padrão duracional, a literatura carece de estudos que reportem os valores de duração das vogais, sejam tônicas ou átonas.

A seguir, apresentamos uma síntese desta seção, considerando as pesquisas resenhadas do sistema vocálico do PB e do Espanhol.

\subsection{Síntese}

Concluindo esta seção, consideramos que, com relação a F1 e F2, com base nos dados expostos, a produção da vogal átona final /e/ (i) é mais alta no $\mathrm{PB}$ do que no Espanhol, devido ao processo de elevação desta vogal, característico do $\mathrm{PB}$, mas não do Espanhol. Além disso, observando-se os dados de Callou, Moraes e Leite $(1996,2002)$ e Santos e Rauber (2016), ainda que a tonicidade vocálica seja distinta, verifica-se que o PB apresenta a vogal /e/ mais alta; e (ii) é centralizada no PB, como apontam Callou, Moraes e Leite (1996, 2002), mas não no Espanhol, sendo, portanto, mais anterior nesta língua. Quanto à duração vocálica, ainda que a literatura careça de descrições detalhadas, principalmente em posição átona final, com base na descrição de Silva (2012), esta referente às vogais postônicas finais da fala brasiliense, e na de Santos e Rauber (2016), por sua vez referente às vogais tônicas de Montevidéu/Uruguai, podemos considerar que a vogal átona final /e/ pode ser mais longa no Espanhol, com uma média de 106 ms (SANTOS; RAUBER, 2016), do que no $\mathrm{PB}$, o qual pode apresentar uma média aproximada de $88 \mathrm{~ms}$ (SILVA, 2012). Além disso, a própria Gramática da RAE destaca que, dentre as vogais átonas, as átonas finais são mais longas no Espanhol. 
Caracterização acústica da vogal átona final /e/ no português porto-alegrense e no espanhol uruguaio | 53

Estes achados referentes aos estudos prévios serviram de base para a hipótese estabelecida neste trabalho, apresentada na seção de Introdução.

No que segue, apresentamos a metodologia aplicada nesta pesquisa.

\section{METODOLOGIA}

Nesta seção, descrevemos os participantes, os instrumentos e procedimentos utilizados na coleta de dados.

\subsection{Participantes}

Esta pesquisa foi realizada com 6 falantes monolíngues de Espanhol (Grupo 1), oriundos de Montevidéu/Uruguai, sendo duas mulheres e quatro homens, e com 8 falantes monolíngues de Português Brasileiro (Grupo 2), naturais de Porto Alegre/RS ou região metropolitana, sendo cinco mulheres e três homens, totalizando, portanto, 14 participantes. A média de idade do Grupo 1 é de 42,17 (DP $=14,48)$, enquanto que a média de idade do Grupo 2 é de 35,8 (DP = 12,09).

É importante mencionar que optamos pelo Espanhol uruguaio, falado em Montevidéu, pela viabilidade da coleta de dados, dado que esta é a capital hispânica mais próxima a Porto Alegre.

\subsection{Instrumentos de coleta}

Para a coleta de dados referentes às produções da vogal átona final /e/, construímos duas Tarefas de Leitura (de frases-veículo), uma em Português e outra em Espanhol. Como frase-veículo, optamos por "DIGO X BEM." para a Tarefa em Português e "DIGO X BIEN." para a Tarefa em Espanhol, sendo X correspondente ao estímulo-alvo ou distrator.

Como forma de controlar algumas variáveis intervenientes, selecionamos os estímulos-alvo com base nos seguintes critérios: (i) palavras não-cognatas ${ }^{14}$, pois a literatura sobre acesso lexical por parte de bilíngues (LEMHÖFER \& DIJKSTRA, 2004) aponta efeito de status cognato em nível semântico. Contudo, como não sabemos se o status

14 Salientamos que não foram utilizadas plataformas online para a classificação das palavras como não-cognatas. Adotamos, portanto, critérios subjetivos. 


\section{4 | Bruna da Rosa de Los Santos e Ubiratã Kickhöfel Alves}

cognato influencia também no nível de produção linguística ${ }^{15}$, optamos por controlar esta variável; (ii) palavras dissílabas ou trissílabas, para que pudéssemos controlar o padrão duracional das palavras; e (iii) palavras paroxítonas, como forma de controlar o padrão acentual das palavras.

Salientamos que foi preciso, ainda, ampliar o número de contextos antecedentes à vogal átona final /e/ para que obtivéssemos equilíbrio quanto à quantidade de estímulos-alvo em cada língua. Portanto, consideramos os estímulos-alvo nos quais o contexto antecedente à vogal átona final /e/ correspondia às consoantes /p, b, k, g/. Não incluímos estímulos nos quais as consoantes antecedentes eram /d, t/ dado o fenômeno de palatalização, frequente em Porto Alegre ${ }^{16}$. No Quadro 1, a seguir, apresentamos os estímulos-alvo e os estímulos distratores utilizados nas Tarefas de Leitura.

Quadro 1: Estímulos-alvo e os estímulos distratores

\begin{tabular}{|c|c|c|c|c|}
\hline Tarefa de Leitura & \multicolumn{2}{|c|}{ Estímulos-alvo } & \multicolumn{2}{|c|}{ Estímulos distratores } \\
\hline & Dissílabos & Trissílabos & Dissílabos & Trissílabos \\
\hline Espanhol & $\begin{array}{l}\text { turbe } \\
\text { nube } \\
\text { pope } \\
\text { tepe } \\
\text { pliegue } \\
\text { cuelgue } \\
\text { bloque } \\
\text { hinque }\end{array}$ & $\begin{array}{l}\text { derrumbe } \\
\text { pruebe } \\
\text { solape } \\
\text { arrope } \\
\text { rezongue } \\
\text { repliegue } \\
\text { achique } \\
\text { meñique }\end{array}$ & $\begin{array}{c}\text { habla } \\
\text { suelo } \\
\text { luna } \\
\text { lleno }\end{array}$ & $\begin{array}{l}\text { abuela } \\
\text { vuelo } \\
\text { suena } \\
\text { bueno }\end{array}$ \\
\hline Português & $\begin{array}{l}\text { sambe } \\
\text { quibe } \\
\text { ergue } \\
\text { sangue } \\
\text { poupe } \\
\text { jipe } \\
\text { baque } \\
\text { bique }\end{array}$ & $\begin{array}{l}\text { esnobe } \\
\text { carimbe } \\
\text { carregue } \\
\text { açougue } \\
\text { entope } \\
\text { estepe } \\
\text { rabisque } \\
\text { sotaque }\end{array}$ & $\begin{array}{l}\text { fala } \\
\text { vila } \\
\text { tolo } \\
\text { treino }\end{array}$ & $\begin{array}{l}\text { lacuna } \\
\text { vacina } \\
\text { abalo } \\
\text { aceno }\end{array}$ \\
\hline
\end{tabular}

Fonte: os autores.

${ }^{15}$ Conforme De Los Santos e Alves (2017), o status cognato "se mostra pertinente para explorar efeitos de ativação interlinguística no que diz respeito, portanto, à produção específica de categorias fonéticofonológicas" (op. cit., p. 7).

${ }^{16}$ Cf. Kamjanecky (2003). 
Caracterização acústica da vogal átona final /e/ no português porto-alegrense e no espanhol uruguaio | 55

Para a construção das Tarefas de Leitura, utilizamos o site randomizer.org, com a finalidade de gerar três ordens randômicas para construir três diferentes conjuntos de slides no programa de apresentação Power Point. Assim, cada língua contou com uma Tarefa de Leitura, composta por três blocos de slides randômicos, os quais apresentaram 16 estímulos-alvo e 8 estímulos distratores, totalizando 24 sentenças a serem lidas por conjunto de slide (totalizando, portanto, 72 sentenças para a Tarefa de Leitura em Espanhol, bem como para a Tarefa de Leitura em Português).

Além das Tarefas de Leitura, esta pesquisa contou com dois Testes de Familiaridade Lexical (adaptado de Lepage, 2015), um em Português e outro em Espanhol. Neste teste, os participantes tiveram que assinalar para cada estímulo, conforme seu conhecimento, uma das seguintes opções: (i) conheço esta palavra e sei seu significado; (ii) conheço esta palavra, mas não lembro seu significado; ou (iii) não conheço esta palavra. As respostas nos forneceram um índice de familiaridade dos participantes com as palavras utilizadas nas Tarefas de Leitura. Todos os estímulos-alvo que não alcançaram $70 \%$ de respostas na alternativa 1 (conheço esta palavra e sei seu significado) foram excluídos da amostra de dados de cada grupo.

Vale ressaltar, ainda, que estavam incluídos nesta pesquisa dois Termos de Consentimento Livre e Esclarecido (um em cada língua) e duas Fichas de Informações do Participante (um em cada língua) ${ }^{17}$.

\subsection{Procedimentos de coleta de dados}

- primeiro procedimento de coleta de dados consistiu na assinatura do Termo de Consentimento Livre e Esclarecido, seguido do preenchimento da Ficha de Informações do Participante. Logo, utilizamos o software Audacity (taxa de amostragem $44.100 \mathrm{~Hz}$ ), um Head Set Microsoft 3.000 e um notebook Positivo Intel Inside para a realização das gravações das Tarefas de Leitura, as quais duraram em torno de 3 a 4 minutos para cada participante. É importante mencionar que a coleta foi realizada individualmente.

17 Estes instrumentos de coleta de dados são discriminados detalhadamente em AUTORA (2017). O projeto de pesquisa que originou este estudo foi aprovado pelo CEP da Instituição Proponente do Projeto sob o número de processo 60718216.9.0000.5347. 
Durante a coleta, o participante foi convidado a sentar-se diante de um notebook, colocar o Head Set e ler o primeiro slide da Tarefa de Leitura (que consiste em um slide explicativo), para que a pesquisadora pudesse configurar o ganho do microfone no software Audacity. Após as configurações realizadas, a pesquisadora responsável pelas coletas, primeira autora deste artigo, deu algumas instruções, tais como: "Você não deve ler pausadamente, tente ler as frases da maneira mais natural possível; não aproxime o microfone, pois já está configurado para esta distância; não há resposta correta para a Tarefa" ${ }^{18}$.

Por último, ao final de cada Tarefa de Leitura, todos os participantes preencheram o Teste de Familiaridade Lexical, correspondente à sua língua. Dessa forma, considerando todos os procedimentos, a coleta de dados durou de 15 a 20 minutos para cada participante.

\section{ANÁLISE E DISCUSSÃO DOS RESULTADOS}

Para todos os áudios de cada participante, foram elaboradas etiquetas/linhas de grade (TextGrids) no software Praat - versão 5.4.18 (BOERSMA; WEENINK, 2015), de forma a facilitar a segmentação da vogal, bem como a medição da duração absoluta da vogal e a medição da duração do enunciado, essa última necessária para o cálculo de duração relativa ${ }^{19}$. Quanto ao recorte da vogal, prosseguimos da seguinte forma: selecionamos a parte estável da vogal; logo, aplicamos um zoom para que aparecesse apenas esta parte estável na tela do Praat; após isso, então, posicionamos o cursor bem no centro dessa parte estável, e por último, solicitamos ao programa os valores de F1 e F2, através do comando Formant listing. Tal método é comumente conhecido como LPC/Linear Prediction Coding (COLANTONI, STEELE, ESCUDERO, 2015).

Após extrairmos os valores referentes à altura vocálica (Formante 1 - F1) e anterioridade/posterioridade vocálica (Formante 2 - F2),

18 Tais instruções foram dadas na língua da Tarefa (Português ou Espanhol).

${ }^{19}$ Conforme Silva (2014), a duração relativa é uma normalização que evita a influência de fatores prosódicos, entre eles, velocidade de fala. Para calculá-la, basta multiplicar por 100 a duração absoluta da vogal e dividir o resultado pela duração do enunciado, obtendo-se, assim, um percentual, ou seja, o quanto do enunciado é ocupado pela vogal. 
Caracterização acústica da vogal átona final /e/ no português porto-alegrense e no espanhol uruguaio | 57 submetemos os dados à plataforma Norm ${ }^{20}$, a fim de normalizá-los, dada a participação de falantes homens e mulheres na amostra. Utilizamos o método de normalização Bark ${ }^{21}$, pois, segundo a literatura (ADANK, SMITS, HOUT, 2004; MACHRY DA SILVA, 2014, 2015), tal método é mais adequado para pesquisas que não mapeiam todo o sistema vocálico, bem como para aquelas que preveem comparações entre diferentes inventários fonológicos.

Com os dados normalizados, os mesmos foram inseridos no Software SPSS (IBM, Versão 21). Realizamos testes de comparações de médias, sendo que para os dados com distribuição normal ${ }^{22}$ foram realizados Teste $t$ de amostras independentes, enquanto que para os dados com distribuição não-normal ${ }^{23}$ foram realizados Teste de duas amostras independentes - Mann-Whitney. Adotamos o nível de significância de .05. A seguir, na Tabela 3, apresentamos os dados quantitativos referentes à altura, anterioridade/posterioridade e duração vocálica.

Tabela 3: Médias (em Bark), Desvios Padrão (DP), Coeficientes de Variação (CV) de F1, F2 e durações em Espanhol/L1 (Grupo 1) e em Português/L1 (Grupo 2)

\begin{tabular}{|c|c|c|c|c|c|c|}
\hline Grupo & F1 & $\mathrm{F} 2$ & Dura & io absolut & ms) e rela & $\mathrm{z}(\%)$ \\
\hline & & & $\begin{array}{c}\text { Dissílaba/ } \\
\text { Sonoro }\end{array}$ & $\begin{array}{c}\text { Dissílaba/ } \\
\text { surdo }\end{array}$ & $\begin{array}{c}\text { Trissílaba/ } \\
\text { sonoro }\end{array}$ & $\begin{array}{c}\text { Trissilaba/ } \\
\text { surdo }\end{array}$ \\
\hline \multirow{6}{*}{$\begin{array}{c}\text { Espanhol } \\
\text { L1 }\end{array}$} & \multirow[b]{2}{*}{10,21} & \multirow[b]{2}{*}{1,49} & 107,47 & 99,64 & 108,44 & 95,85 \\
\hline & & & $\mathrm{DP}=11,56$ & $\mathrm{DP}=21,07$ & $\mathrm{DP}=13,79$ & $\mathrm{DP}=5,61$ \\
\hline & $\mathrm{DP}=0,23$ & $\mathrm{DP}=0,07$ & $C V=10,75$ & $C V=21,14$ & $C V=12,71$ & $C V=5,85$ \\
\hline & \multirow{3}{*}{$C V=2,25$} & \multirow{3}{*}{$C V=4,67$} & 9,30 & 6,67 & 7,56 & 6,80 \\
\hline & & & $\mathrm{DP}=3,87$ & $\mathrm{DP}=1,02$ & $\mathrm{DP}=0,85$ & $\mathrm{DP}=1,46$ \\
\hline & & & $C V=41,61$ & $C V=15,29$ & $C V=11,25$ & $C V=21,47$ \\
\hline
\end{tabular}

${ }^{20}$ Disponível em <http://lingtools.uoregon.edu/norm/norm1.php〉.

${ }^{21}$ A normalização em Bark converte os valores de $\mathrm{Hz}$ em valores z-score, além de se diferenciar da medição em Hertz pelo fato de os valores de F1 em Bark serem diretamente proporcionais à altura da vogal.

22 Os testes de normalidade, rodados no SPSS, foram os testes de Kolmogorov e Shapiro-Wilk. Foram considerados com distribuição normal os dados com $\mathrm{p}>.05$ nos testes de normalidade.

${ }^{23}$ Foram considerados com distribuição não-normal os dados com $\mathrm{p}<.05$ nos testes de normalidade. 
58 | Bruna da Rosa de Los Santos e Ubiratã Kickhöfel Alves

\begin{tabular}{c|c|c|c|c|c|c}
\hline & & 1,67 & 64,82 & 51,04 & 59,8 & 38,43 \\
$\begin{array}{c}\text { Português } \\
\text { L1 }\end{array}$ & DP=0,46 & $\mathrm{DP}=0,18$ & $\begin{array}{c}\text { DP=9,57 } \\
\mathrm{CV}=14,76\end{array}$ & $\begin{array}{c}\mathrm{DP}=6,84 \\
\mathrm{CV}=13,4\end{array}$ & $\begin{array}{c}\mathrm{DP}=6,94 \\
\mathrm{CV}=11,60\end{array}$ & $\begin{array}{c}\mathrm{DP}=6,24 \\
\mathrm{CV}=16,23\end{array}$ \\
& $\mathrm{CV}=4,10$ & $\mathrm{CV}=10,77$ & 4,88 & 4,01 & 4,48 & 2,81 \\
& & & $\begin{array}{c}\mathrm{DP}=0,84 \\
\mathrm{CV}=17,21\end{array}$ & $\begin{array}{c}\mathrm{DP}=0,91 \\
\mathrm{CV}=22,69\end{array}$ & $\begin{array}{c}\mathrm{DP}=1,08 \\
\mathrm{CV}=24,1\end{array}$ & $\begin{array}{c}\mathrm{DP}=0,74 \\
\mathrm{CV}=26,33\end{array}$ \\
\hline
\end{tabular}

Fonte: os autores.

Observando a tabela acima, em termos descritivos, podemos notar que a vogal átona final /e/ é mais alta no $\mathrm{PB}(\mathrm{M}=11,20)$ do que no Espanhol $(M=10,21)$. No eixo de anterioridade/posterioridade, a vogal já mencionada é mais anterior na Língua Espanhola $(M=1,49)$, enquanto no $\mathrm{PB}$ a produção é mais centralizada $(\mathrm{M}=1,67)$. Quanto à duração vocálica, observamos uma maior duração no Espanhol monolíngue, em todos os contextos mapeados (palavras dissílabas/trissílabas com contexto sonoro/surdo anterior à vogal). Realizamos os testes de normalidade (Kolmogorov-Smirnov e Shapiro-Wilk), através do software SPSS (Versão 21), os quais indicaram uma distribuição normal dos dados ( $p>, 05)$, com exceção da duração absoluta do PB em palavras dissílabas de contexto antecedente surdo (ex.: poupe); da duração relativa do PB em palavras dissílabas de contexto antecedente sonoro (ex.: sambe); da duração relativa do $\mathrm{PB}$ em palavras trissílabas de contexto antecedente surdo (ex.: estepe); da duração relativa do Espanhol em palavras trissílabas de contexto antecedente surdo (ex.: achique). Considerando esses resultados quanto à normalidade, prosseguimos com testes paramétricos para as variáveis com distribuição normal (Teste t para amostras independentes) e com testes não-paramétricos para as variáveis que não apresentaram distribuição normal dos dados (Teste de duas amostras independentes Mann-Whitney). No Gráfico 1, a seguir, reproduzimos as produções da vogal átona final /e/ pelos Grupos 1 e 2 . 
Caracterização acústica da vogal átona final /e/ no português porto-alegrense e no espanhol uruguaio | 59

Gráfico 1: vogal átona final /e/ produzida pelo Grupo 1 (monolíngues de Espanhol) e pelo Grupo 2 (monolíngues de PB)

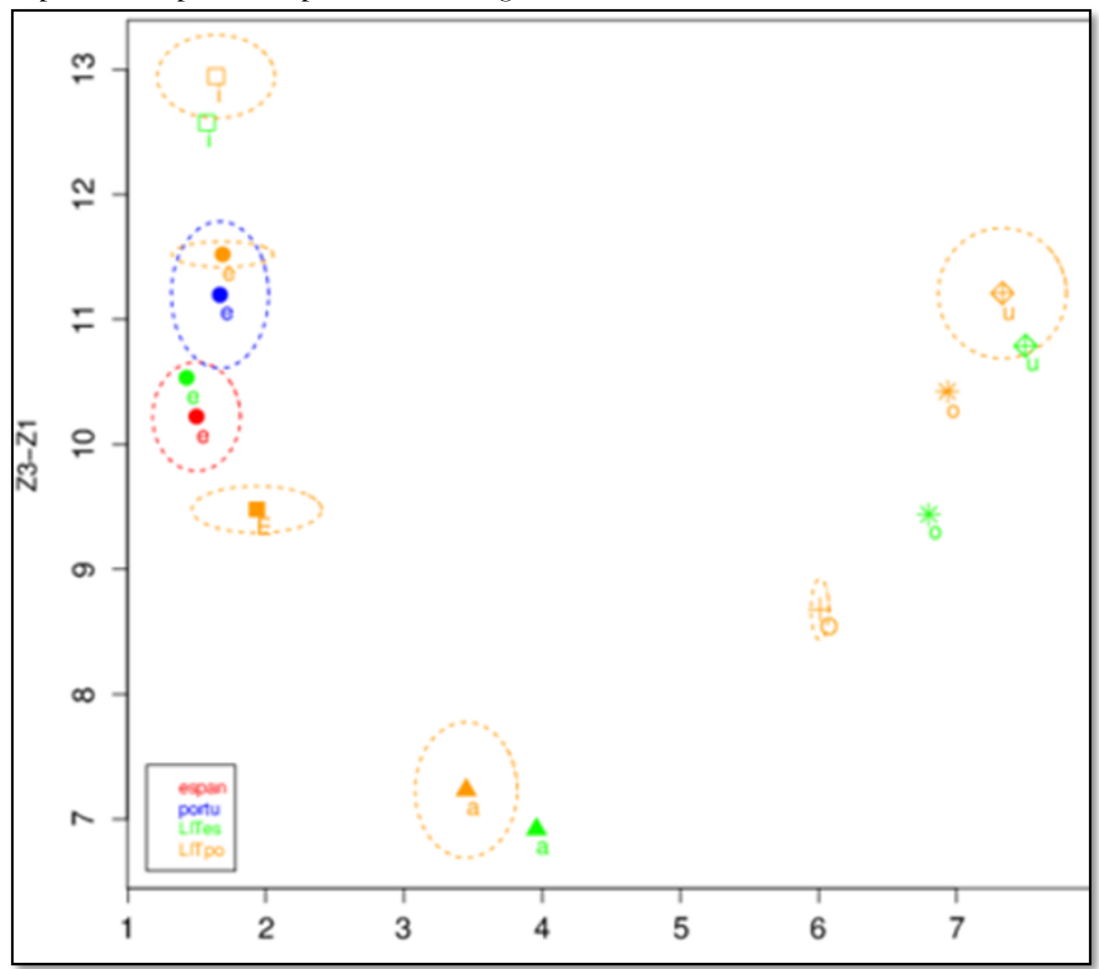

Fonte: elaboração dos autores. Legenda: a cor vermelha corresponde à vogal átona final /e/ produzida pelos monolíngues de Espanhol; a cor azul corresponde à vogal átona final /e/ produzida pelos monolíngues de $\mathrm{PB}$; a cor verde corresponde às vogais tônicas do Espanhol, mapeadas por Aronson et al. (2000); a cor laranja corresponde às vogais tônicas do PB, mapeadas por Escudero et al. (2009).

Conforme o Gráfico 1, não há nenhuma sobreposição entre as produções do Grupo 1 e as produções do Grupo 2. Ao realizarmos um Teste $-\mathrm{t}$ de amostras independentes, os resultados apresentaram uma altura vocálica maior para o Português Brasileiro $(\mathrm{M}=11,20, \mathrm{DP}=0,46)$ do que para o Espanhol $(\mathrm{M}=10,21, \mathrm{DP}=0,23), \mathrm{t}(10,708)=-5,208, \mathrm{p}<$ 
60 | Bruna da Rosa de Los Santos e Ubiratã Kickhöfel Alves

, 001 , I.C $95 \%_{t}=-1,40 /-0,57, d=-2,59^{24}$, I.C. $95 \%_{d}=-4,02 /-1,16 . T a l$ resultado corrobora o que a literatura descreve, dado que as vogais átonas finais no PB, faladas em Porto Alegre/RS, são elevadas/alçadas; portanto, tais vogais não são produzidas como médias, diferenciando-se mais ainda dos padrões de altura do Espanhol. Para F2, os resultados do teste também apresentaram uma diferença significativa entre as duas línguas, uma vez que a vogal átona final /e/ do Espanhol é mais anterior $(\mathrm{M}=$ $1,49, \mathrm{DP}=0,07)$ do que sua contraparte no Português Brasileiro $(\mathrm{M}=$ $1,67, \mathrm{DP}=0,18), \mathrm{t}(9,857)=-2,348, \mathrm{p}=, 041$, I.C $95 \%_{\mathrm{t}}=-0,33 / 0,008, \mathrm{~d}$ $=-1,24$, I.C. $95 \%_{d}=-2,39 /-0,08$. Dessa forma, confirmamos que as vogais átonas do $\mathrm{PB}$ são mais centralizadas, considerando o eixo de anterioridade/posterioridade, em relação às vogais átonas do Espanhol.

Quanto à duração vocálica, observamos diferença significativa entre as línguas em todas as condições (palavra dissílaba/trissílaba; contexto sonoro/surdo), tanto na duração absoluta como na duração relativa. De forma específica, verificaram-se diferenças significativas nos seguintes contextos:

(i) duração absoluta de palavras dissílabas com contexto antecedente sonoro, dado que o Espanhol apresentou vogais mais longas $(\mathrm{M}=107,47, \mathrm{DP}=11,56)$ do que o Português $(\mathrm{M}=64,82, \mathrm{DP}=9,57), \mathrm{t}$ $(12)=7,556, p<, 001$, I.C. $95 \%_{t}=30,35 / 54,94, d=4,08$, I.C. $95 \%_{d}=$ 2,23/5,92;

24 Para esta comparação (monolíngues Espanhol - monolíngues PB), utilizamos uma calculadora online de Unequal samples para estimar o Tamanho do Efeito (d), disponível em <psychometrica.de/effect_size.html\#cohend>. Além disso, salientamos que, conforme apontam Dancey e Reidy (2006), "O tamanho do efeito é a magnitude da diferença entre condições ou o poder de um relacionamento. (...) d é a distância entre as duas médias em termos de desvios padrões. Se existe uma área grande sobreposta entre os dois grupos, o efeito será relativamente pequeno; se existe uma área pequena sobreposta, o efeito será relativamente grande." (op. cit., p. 251). Com base em Cohen (1988), Dancey e Reidy (2006) apresentam parâmetros a partir dos quais podemos considerar um efeito como "grande" ou como "pequeno", sendo eles: $d=0,20$ (efeito pequeno), $d=0,50$ (efeito médio) e d $=0,80$ (efeito grande). 
Caracterização acústica da vogal átona final /e/ no português porto-alegrense e no espanhol uruguaio $\mid 61$

(ii) duração absoluta de palavras dissílabas com contexto antecedente surdo, dado que as vogais do Espanhol foram mais longas (M $=99,64, \mathrm{DP}=21,07$, mediana $=92,91)$ do que as do Português $(\mathrm{M}=$ 51,04, DP $=6,84$, mediana $=47,37), U=0,000(z=-3,09), p=, 001113$, $\mathrm{d}=3,33$, I.C. $95 \% \mathrm{~d}_{\mathrm{d}}=1,70 / 4,96$;

(iii) duração absoluta de palavras trissílabas com contexto antecedente sonoro, pois as vogais do Espanhol foram mais longas $(\mathrm{M}=$ $108,44, \mathrm{DP}=13,79)$ do que as do Português $(\mathrm{M}=59,80, \mathrm{DP}=6,94)$, $\mathrm{t}$ $(12)=8,689, p<, 001$, I.C. $95 \%_{t}=36,44 / 60,83, d=4,69$, I.C. $95 \%_{d}=$ 2,65/6,73;

(iv) duração absoluta de palavras trissílabas com contexto antecedente surdo, dado que as vogais do Espanhol foram mais longas (M $=95,85, \mathrm{DP}=5,61)$ do que as do Português $(\mathrm{M}=38,43, \mathrm{DP}=6,24), \mathrm{t}$ $(11,51)=18,043, \mathrm{p}<, 001$, I.C. $95 \%_{t}=50,45 / 64,38, d=9,59$, I.C. $95 \% \%_{d}$ $=5,88 / 13,30$;

(v) duração relativa de palavras dissílabas com contexto antecedente sonoro, dado que as vogais do Espanhol ocuparam uma porção maior do enunciado $(\mathrm{M}=9,30$, $\mathrm{DP}=3,87)$ do que as vogais do Português $(\mathrm{M}=$ $4,88, \mathrm{DP}=0,84), \mathrm{t}(12)=3,167, \mathrm{p}=, 008$, I.C. $95 \% \%_{\mathrm{t}}=1,37 / 7,46, \mathrm{~d}=$ 1,71 , I.C. $95 \% \%_{d}=0,47 / 2,94$;

(vi) duração relativa de palavras dissílabas com contexto antecedente surdo, dado que as vogais do Espanhol ocuparam uma porção maior do enunciado $(\mathrm{M}=6,67, \mathrm{DP}=1,02)$ do que as do Português $(\mathrm{M}=4,01, \mathrm{DP}=$ 0,91), t $(12)=5,122, \mathrm{p}<, 001$, I.C. $95 \%_{t}=1,52 / 3,78, d=2,77$, I.C. $95 \% \%_{d}$ $=1,30 / 4,25$;

(vii) duração relativa de palavras trissílabas com contexto antecedente sonoro, dado que as vogais do Espanhol ocuparam uma porção maior do enunciado $(\mathrm{M}=7,55, \mathrm{DP}=0,85)$ do que as vogais do Português $(\mathrm{M}=$ $4,48, \mathrm{DP}=1,08), \mathrm{t}(12)=5,715, \mathrm{p}<, 001$, I.C. $95 \%_{\mathrm{t}}=1,89 / 4,24, \mathrm{~d}=$ 3,09, I.C. $95 \% \%_{\mathrm{d}}=1,53 / 4,66$;

(viii) duração relativa de palavras trissílabas com contexto antecedente surdo, dado que as vogais do Espanhol ocuparam uma porção maior do enunciado $(\mathrm{M}=6,80, \mathrm{DP}=1,46)$ do que as vogais do Português $(\mathrm{M}=$ 2,81, DP $=0,74), \mathrm{t}(6,943)=6,105, \mathrm{p}=, 001$, I.C. $95 \% \%_{\mathrm{t}}=2,44 / 5,53, \mathrm{~d}=$ 3,63 , I.C. $95 \% \%_{\mathrm{d}}=1,91 / 5,34$.

Com base nos resultados expostos acima, confirmamos os dados da literatura (CALLOU, MORAES, LEITE, 1996, 2002; SANTOS, RAUBER, 2016; SILVA, 2012), visto que, no Português, a vogal átona 
62 | Bruna da Rosa de Los Santos e Ubiratã Kickhöfel Alves

final /e/ é mais alta, devido ao processo de elevação/alçamento; além disso, a vogal átona final do Português é centralizada, enquanto no Espanhol a mesma vogal é mais anterior; por último, em posição átona final, em termos duracionais, a vogal é mais longa no Espanhol do que no Português Brasileiro, tanto em termos de duração absoluta como relativa. Ainda que os Intervalos de Confiança (I.C. 95\%) das diferenças entre as médias sejam amplos, todos os valores do Tamanho de Efeito (d) foram altos. Portanto, cabe mencionar que os efeitos encontrados nesta comparação (monolíngues $\mathrm{PB}$ versus monolíngues Espanhol) são grandes (menor efeito encontrado $=-1,24 /$ maior efeito encontrado $=9,59$ ), ou seja, há baixa sobreposição entre os grupos e, consequentemente, maior diferença entre eles.

Acreditamos que, com esta descrição, o presente trabalho tenha prestado uma importante contribuição, a de colaborar com os estudos descritivos de variedades do Português Brasileiro e do Espanhol. A seguir, apresentamos nossas considerações finais.

\section{CONSIDERAÇÕES FINAIS}

Nesta pesquisa, tivemos como propósito principal mapear acusticamente as produções da vogal átona final /e/, tanto no PB portoalegrense como no Espanhol uruguaio. Além disso, realizamos uma comparação estatística entre os valores acústicos dessas duas variedades, evidenciando, assim, efeitos de língua. Dessa forma, a hipótese de pesquisa foi corroborada. Em conformidade com a literatura descritiva, sociolinguística e acústica, os resultados indicaram que a vogal átona final /e/ da capital gaúcha é mais alta, centralizada e mais curta do que a mesma vogal produzida por falantes do Espanhol uruguaio. Considerando a escassez de trabalhos com refinamento acústico, principalmente de vogais átonas, tanto em PB como em Espanhol, acreditamos que a presente pesquisa contribui de forma satisfatória ao apresentar dados de descrição do PB e do Espanhol como L1. Além disso, acreditamos, ainda, que os estudiosos do desenvolvimento vocálico por parte de bilíngues Português/Espanhol ou Espanhol/Português possam se munir dos dados aqui apresentados para a construção de suas hipóteses de pesquisa, dado que é extremamente necessário conhecer a produção típica da L1 dos aprendizes, considerando suas particularidades fonéticofonológicas.

Salientamos que a principal limitação deste estudo foi ter contado com poucos participantes para a constituição das amostras de cada grupo, 
Caracterização acústica da vogal átona final /e/ no português porto-alegrense e no espanhol uruguaio | 63 o que prejudica na generalização dos resultados. $O$ motivo do baixo número de participantes se deu em função da dificuldade de encontrar indivíduos que estivessem dentro dos critérios estabelecidos para participação, e que, além disso, tivessem interesse e disponibilidade de participar.

Em pesquisas futuras, pretendemos conseguir uma amostra maior de participantes em ambas as línguas, além de mapear o restante do sistema vocálico em posições átonas, bem como realizar a testagem de efeitos de frequência lexical, de outros contextos consonantais antecedentes à vogal átona final /e/, da familiaridade lexical dos bilíngues em relação aos estímulos e de outros tipos de produção linguística, como fala menos monitorada. Apesar das limitações desta pesquisa, ressaltamos, novamente, as contribuições do presente estudo, ao poder vir a servir como insumo empírico para inúmeras pesquisas em andamento.

\section{REFERÊNCIAS}

ALARCOS LLORACH, E. Fonología Española. La Habana: Instituto Cubano del libro, 1975.

AMARAL, M. P. As proparoxitonas: Teoria e Variação. 2000. 220f. Tese de Doutorado em Letras - Pontifícia Universidade Católica do Rio Grande do Sul, Porto Alegre, 2000.

AROSON, L. et al. Características acústicas de las vocales del español rioplatense. In: Fonoaudiológica, v. 46, n. 2, p. 12-20, 2000.

BECKNER, C.; et al. Language is a Complex Adaptative System: Position Paper. In: Language Learning, 2009.

BISOL, L. Harmonização vocálica. 1981. Trabalho de conclusão de curso (Tese) - Doutorado em Letras, Universidade Federal do Rio de Janeiro, Rio de Janeiro, 1981.

. A neutralização das átonas. In: Revista Letras, n. 61, p. 273-283, 2003.

A simetria no sistema vocálico do Português Brasileiro. In: Revista de Estudos linguísticos do Porto, v. 5, p. 41-52, 2010.

BOERSMA, P. A.; WEENINK, D. Praat: doing phonetics by computer. Disponível em <www.praat.org>. Acesso em: 2 set. 2015.

BORTONI, S. M.; et al. Um estudo preliminar do /e/ pretônico. In:

Cadernos de Estudos Linguísticos. Campinas, p. 75-90, 1991. 
$64 \mid$ Bruna da Rosa de Los Santos e Ubiratã Kickhöfel Alves

BRISOLARA, L. B.; SEMINO, M. J. I. Cómo pronunciar el español? La enseñanza de la fonética y la fonología para brasileños: Ejercicios prácticos. Campinas, SP: Pontes Editores, 2014.

; SOLÉ, A. S. A produção das vogais átonas finais do Português por falantes nativos do Espanhol colombiano. In: ALVES, U. K (Org.). Aquisição fonético-fonológica de língua estrangeira - Investigações Rio-Grandenses e Argentinas em discussão. Campinas, SP: Pontes Editores, 2016.

BUTRAGUEÑO, P. M. Vocales en contexto. Disponível em <http://lef.colmex.mx/Sociolinguistica/Cambio\%20y\%20variacion /VOCALES\%20EN\%20C ONTEXTO.pdf>.

; LASTRA, Y. (coord.). Introducción. In: Corpus sociolingüístico de la Ciudad de México. Materiales de Preseea-México. Vol. 1: Hablantes de instrucción superior. México: El Colegio de México, 2011.

CALlOU, D.; MORAES, J. A; LEITE, Y. O vocalismo do português do Brasil. In: Letras de Hoje, Porto Alegre, v. 31, no 2, p. 27-40, 1996.

; LEITE, Y. Iniciação à fonética e à fonologia. Rio de Janeiro: Jorge Zahar, 2000. $7^{\text {a }}$ ed.

; ______; MORAES, J. A. A elevação das pretônicas no português do Brasil: processo (s) de variação estável. In: Letras de Hoje, Porto Alegre, v. 37, n 1, p. 9-24, 2002.

CAMARA Jr, J. M. Estrutura da lingua portuguesa. Petrópolis (RJ): Vozes, 1970.

CARNIATO, M. C. A neutralização das vogais postônicas finais na comunidade de Santa Vitória do Palmar. 2000. 111f. Dissertação de Mestrado em Letras - Universidade Católica de Pelotas, Rio Grande do Sul, 2000.

COHEN, J. Statistical power analysis for the behavioral sciences (2nd ed.). Hillsdale, NJ: Lawrence Earlbaum Associates, 1988.

COLANTONI, L.; STEELE, J.; ESCUDERO, P. Second language speech Theory and practice. U.K.: Cambridge University Press, 2015

CONDE, X. F. Introducción a la fonética y fonología del español. In: Ianua, Revista Philologica Romanica, 2001. ISSN 1616-413X

DANCEY, C. P.; REIDY, J. Estatística sem matemática para Psicologia Usando SPSS para Windows. Porto Alegre: Artmed, 2006.

DE BOT, K.; et al. Dynamic Systems Theory as a comprehensive theory of second language development. In: Contemporany Approaches to Second Language Acquisition, 2013. 
Caracterização acústica da vogal átona final /e/ no português porto-alegrense e no espanhol uruguaio $\mid 65$

DE LOS SANTOS, B. R. A produção da vogal átona final /e/ por porto alegrenses aprendizes de Espanhol como Segunda Lingua (L2): Uma investigação sobre atrito linguístico em ambiente de L2 nãodominante. 2017. Trabalho de conclusão de curso (Dissertação) Mestrado em Letras, Universidade Federal do Rio Grande do Sul, Rio Grande do Sul, 2017.

; ALVES, U. K. A produção da vogal átona final /e/ em Português Brasileiro (L1) e em Espanhol (L2) - Um estudo exploratório. In: Matraga: Estudos linguísticos e literários, v. 41, 2017.

ESCUDERO, P; et al. A cross-dialect acoustic description of vowels: Brazilian and European Portuguese. In: Acoustical Society of America, v. 126, n. 3, p. 1379-139, 2009.

KAMIANECKY, F. Palatalização das oclusivas dentais nas comunidades de Porto Alegre e Florianópolis: uma análise quantitativa. 2003. $114 \mathrm{f}$. Dissertação de Mestrado em Letras - Pontifícia Universidade Católica do Rio Grande do Sul, Rio Grande do Sul, 2003

LEMHÖFER, K.; DIJKSTRA, T. Recognizing cognates and interlexical homographs: Effects of code similarity in language specific and generalized lexical decision. In: Memory Eु Cognition, 32, p. 533-550, 2004.

LEPAGE, A. The Contribution of Word Stress and Vowel Reduction to the Intelligibility of the Speech of Canadian French Second Language Learners of English. Trabalho de conclusão de curso (Tese) - Doutorado em Linguística, Universidade Laval, Canadá, 2015.

LINK, E. R. Elevação das vogais médias átonas em posição final absoluta em Esquina Barra Funda - Novo Machado - RS. 2015. 104f. Dissertação de Mestrado em Letras - Universidade Federal do Rio Grande, Rio Grande do Sul, 2015.

LIPSKI, J. M. Español de América. Madrid: Cátedra, 2007

LUÍS, C. R.; GARCÍA JURADO, M. A. Desplazamientos fonéticos de vocales españolas. In: Letras de Hoje, v. 18, no 4, p. 98-109, 1983. Disponível em <http://revistaseletronicas.pucrs.br/ojs/index.php/fale/article/view /17715/11411>. Acesso em: 15 de maio de 2017.

MACHRY DA SILVA, S. M. Elevação das vogais médias átonas finais e nãofinais no português falado em Rincão Vermelho - RS. 2009. $172 \mathrm{f}$. Dissertação de Mestrado em Letras - Universidade Federal do Rio Grande do Sul, Rio Grande do Sul, 2009. 
66 | Bruna da Rosa de Los Santos e Ubiratã Kickhöfel Alves

Aprendizagem fonológica e alofônica em L2: Percepção e produção das vogais médias do português por falantes nativos do espanhol. 2014. 257f. Tese de Doutorado em Letras - Pontifícia Universidade Católica do Rio Grande do Sul, Rio Grande do Sul, 2014.

A produção das vogais médias tônicas do Português (L2) por falantes nativos do Espanhol. In: ALVES, U. K.; CARDOSO, W. (org.). ORGANON. Porto Alegre: UFRGS, v. 1, n. 1. p. 91-108, 2015. ISSN 0102-6267

MARGOTTI, F. W. Difusão Sócio-geográfica do português em contato com o italiano no sul do Brasil. 2004. 314f. Tese de Doutorado em Letras Universidade Federal do Rio Grande do Sul, 2004.

MATZENAUER, C. L. B.; et al. Vogais em posição postônica final: Percepção e produção (No sul do Brasil). In: Revista da ABRALIN, v. 14, n. 1, 2015. ISSN 2178-7603

MILESKI, I. A elevação das vogais médias átonas finais no português falado por descendentes de imigrantes poloneses em Vista Alegre do Prata - RS. 2013. 152f. Dissertação de Mestrado em Letras - Pontifícia Universidade Católica do Rio Grande do Sul, Rio Grande do Sul, 2013.

NAVARRO TOMÁS, T. Manual de pronunciación española. Madri: Consejo superior de investigaciones científicas, 2004.

NORM.

Disponivel

em

<http://lingtools.uoregon.edu/norm/norm1.php>. Acesso em: 13 de julho de 2017.

SANTOS, G. R.; RAUBER, A. S. Percepção e produção das vogais medias do Espanhol/LE. In: ALVES, U. K (Org.). Aquisição fonéticofonológica de lingua estrangeira: Investigações Rio-Grandenses e Argentinas em discussão. Campinas, SP: Pontes Editores, 2016.

SCHMITT, C. J. Redução vocálica postônica e estrutura prosódica. 1987. $139 \mathrm{f}$. Dissertação de Mestrado em Letras - Universidade Federal do Rio Grande do Sul, Rio Grande do Sul, 1987.

SILVA, A. H. P. Organização temporal de encontros vocálicos no Português Brasileiro e a relação entre Fonética e Fonologia. In: Letras de Hoje, v. 49, n 1, p. 11-18, 2014.

SILVA, R. O. Características acústicas e articulatórias das vogais postônicas na variedade do Português Brasiliense. 2012. 133f. Dissertação de Mestrado em Letras - Universidade de Brasília, Distrito Federal, 2012.

SOUZA, S. S. O alçamento das vogais médias átonas finais: uma interface entre aquisição da linguagem e variação linguística. 2015. 265f. Tese de 
Caracterização acústica da vogal átona final /e/ no português porto-alegrense e no espanhol uruguaio $\mid 67$

Doutorado em Letras - Pontifícia Universidade Católica do Rio Grande do Sul, Rio Grande do Sul, 2015

REAL ACADEMIA ESPAÑOLA; ASOCIACIÓN DE ACADEMIAS DE

LA LENGUA ESPAÑOLA. Nueva gramática de la lengua española: fonética y fonología. Barcelona: Espasa, 2011.

VIEIRA, M. J. B. Neutralização das vogais médias postônicas. 1994. Trabalho de conclusão de curso (Dissertação) - Mestrado em Letras, Universidade Federal do Rio Grande do Sul, Rio Grande do Sul, 1994.

. As vogais médias postônicas: uma análise variacionista. In: BISOL, L; BRESCANCINI, C. R. (org.). Fonologia e variação: recortes do português brasileiro. Porto Alegre: EDIPUCRS, 2002. p. 127-159.

Recebido em: 08/12/2018

Aceito em: 12/01/2019 